\title{
Platelet secretion from dense and $\alpha$-granules in vitro in migraine with or without aura
}

\author{
G D'Andrea, L Hasselmark, M Alecci, A Cananzi, F Perini, K M A Welch
}

Headache and Stroke Center, Department of Neurology, San Bortolo Hospital, Viale Rodolfi 37, 36100 Vicenza, Italy G D'Andrea L Hasselmark $M$ Alecci A Cananzi F Perini

Department of Neurology, Henry Ford Hospital, 2799 West Grand

Boulevard, Detroit, MI 48202, USA K M A Welch

Correspondence to: Dr G D'Andrea, Headache and Stroke Center, Department of Neurology, San Bortolo Hospital, Viale Rodolfi 37, 36100 Vicenza, Italy.

Received 18 May 1993 and in revised form 9 August 1993. Accepted 17 August 1993

\begin{abstract}
Several studies in vivo indicate platelet activation in migraine, as reflected by increased plasma concentrations of platelet secretory products. In vitro data on platelet secretion are scant, which prompted an investigation into agonistinduced platelet aggregation and secretion in platelets from patients with migraine. Sixty two patients with migraine with aura (MA) and 41 with migraine without aura (MwA) were studied during a headache-free phase, together with 26 healthy controls. Platelet aggregation and secretion in platelet-rich plasma were induced by collagen and platelet activating factor (PAF). Serotonin was measured by high performance liquid chromatography and platelet factor 4 (PF4) with an enzyme immunoassay kit. There were no significant aberrations in platelet aggregation in those with migraine compared with healthy controls. The platelet PF4 secretion induced by PAF (1.0 and $0.1 \mu \mathrm{M})$ was increased in MwA $(p<0.05, p<0.0001)$ compared with controls, and there was a similar trend in MA (NS, $p<0.01$ ). By contrast, the PF4 secretion induced by collagen $(0.5$ and $2.0 \mu \mathrm{g} / \mathrm{ml})$ was reduced in $M A$ (p $<0.01$ and $p<0.05$ ). Further, the MA group exhibited increased basal intraplatelet serotonin concentrations $(p<0.0001)$ and increased serotonin secretion induced by both concentrations of collagen $(p<0.0001)$ and PAF $(p<0.001)$. The data indicate an abnormal platelet a-granule secretion in those with migraine, and focus attention on PAF as a possible factor contributing to the platelet activation associated with migraine. The increased platelet content and secretion of serotonin was specific to MA, and may reflect different serotonin turnover in the two clinical migraine types.
\end{abstract}

(F Neurol Neurosurg Psychiatry 1994;57:557-561)

Table 1 Demographic description of the study sample

\begin{tabular}{llllcll}
\hline & Males & Females & $\begin{array}{l}\text { Age* } \\
(y)\end{array}$ & $\begin{array}{l}\text { Frequency* } \\
\text { (attacks/y) }\end{array}$ & $\begin{array}{l}\text { Duration* } \\
\text { (hours) }\end{array}$ & $\begin{array}{l}\text { Pain } \\
\text { intensityt }\end{array}$ \\
\hline Migraine with aura & 38 & 24 & $27(13-60)$ & $5(1-10)$ & $12(2-72)$ & $1-3$ \\
Migraine without aura & 23 & 18 & $33(12-52)$ & $36(12-60)$ & $14(3-72)$ & $2-3$ \\
Healthy controls & 13 & 13 & $31(18-57)$ & & & \\
\hline
\end{tabular}

*Values are median (range)

$+1=$ light $2=$ medium $3=$ strong.

Platelet activation in association with migraine was first suggested by findings in the early 1960s. These were indicative of serotonin release from circulating platelets during the attack, ${ }^{1}$ thereby initiating the still ongoing discussion on the role of platelets and serotonin in migraine. Due to the important role attributed to serotonin, platelet studies in migraine have focused, for the most part, on the serotonin-related aspects of platelet function and metabolism.

Other reflections of in vivo platelet activation in migraine are increased plasma concentrations of the platelet $a$-granule proteins, $\beta$-thromboglobulin $(\beta$-TG) and platelet factor 4 (PF4). ${ }^{23}$ Although these concentrations are also raised in the headache-free periods, the increases are apparently particularly pronounced in association with attacks, indicating that the postulated serotonin release from dense granules during migraine attacks is parallelled by $a$-granule secretion.

Despite this evidence in vivo of platelet hypersecretion in migraine, there have been few in vitro studies of platelet secretion. Often, platelet aggregation has been used as the solitary measure of platelet function. Coupled measurements of agonist-induced platelet aggregation and the secretion from dense and $a$-granules, could increase knowledge about factors causing platelet activation in migraine, and add to the understanding of the possible role of platelets in the pathophysiology of migraine attacks.

Accordingly, we determined aggregation and secretion, induced by collagen and platelet activating factor (PAF), in platelets from subjects with migraine with aura (MA) and migraine without aura (MwA) during a headache-free phase.

\section{Materials and methods}

STUDY SAMPLE

We studied 62 patients with MA (38 males, 24 females) and 41 patients with MwA (23 males, 18 females) (table 1 ). The clinical diagnosis was made from the International Headache Society classification. ${ }^{4}$ None of the patients had mixed headaches or concomitant diseases. The patients with migraine were studied during a headache-free phase, and had been free of an attack for at least three days. The control sample consisted of 26 healthy volunteers (13 males, 13 females) who were matched for age and sex with the patients. Any headache within two weeks was treated with paracetamol. Apart from this, all subjects disclaimed taking any drugs (includ- 
ing oral contraceptives) for at least two weeks before the study.

\section{BLOOD SAMPLING}

Blood was drawn from an antecubital vein at 0900 from subjects in the supine position after overnight fasting. Blood was drawn on one occasion from each male subject and, in view of the considerable variations in platelet function during the course of the menstrual cycle, on three occasions from all female subjects; in the early follicular phase, midphase (15 days after onset), and late luteal phase. The mean value of these three samples was used in the statistical evaluation.

PREPARATION OF PLATELET-RICH PLASMA

Blood was anticoagulated with a $1 / 10$ volume of $3.8 \%$ sodium citrate solution $(w / v)$ and platelet-rich plasma was obtained by centrifugation at $165 \times g$ for 15 minutes at room temperature. The platelet number was adjusted to $350000 / \mu \mathrm{l}$ with autologous platelet-poor plasma obtained by centrifugation of plateletrich plasma at $2000 \times g$ for 15 minutes.

PLATELET AGGREGATION

Platelet aggregation in $1.0 \mathrm{ml}$ platelet-rich plasma was studied with a Chrono-Log aggregometer (Chrono-Log Corp, Haverton, PA, USA). Platelet aggregation was determined as the percentage change in light transmission (T) and the maximal light transmission was set with platelet poor plasma. The agonists were added in $10 \mu \mathrm{l}$ volumes. The aggregation velocity $\left(\mathrm{V}_{\max }\right)$ was determined as the maximal percentage of increase in $\mathrm{T} / \mathrm{min}$ during the first minute after shape change, and maximal aggregation $\left(A_{\max }\right)$ as percentage increase in $T$ when aggregation had reached its final plateau. The agonists used were collagen $(0.5$ and $2 \cdot 0 \mu \mathrm{g} / \mathrm{ml}$ ) and PAF (1-O-alkyl-O-acetyl$s n$-glycero-3-phosphorylcholine; $0 \cdot 1$ and $1 \cdot 0$ $\mu \mathrm{M})$. PAF and collagen were purchased from Sigma Chemical Co, St Louis, MO, USA. Three minutes after addition of the agonist, the sample was rapidly transferred from the aggregation vial into an Eppendorf tube and pelleted by centrifugation for two minutes at $14000 \mathrm{rpm}$ in an Eppendorf 5415 centrifuge.

DETERMINATION OF PF4 RELEASE

The supernatant fraction was kept stored at $-80^{\circ} \mathrm{C}$ until analysis of PF4 by a commercial enzyme-immunoassay kit (Asserachrom, Boehringer Mannheim).

\section{DETERMINATION OF SEROTONIN RELEASE}

The platelet pellet was resuspended in $1 \mathrm{ml}$ of physiological saline, and the suspension was sonicated at room temperature for three minutes with a B Braun 2000 sonicator at -60-output. The suspension was then deproteinised by adding $30 \mathrm{mg}$ of 5-sulpho-salicylate-dihydrate and centrifuging for two minutes at $14000 \mathrm{rpm}$ in an Eppendorf centrifuge. The supernatant was stored at $-80^{\circ} \mathrm{C}$ until high performance liquid chromatography (HPLC) mainly according to the methodology previously described in detail, 5 but with a modified mobile phase consisting of $125 \mathrm{mM} \mathrm{Na}_{2} \mathrm{HPO}_{4}, 100 \mathrm{mM}$ citric acid, $0.5 \mathrm{mM}$ octyl sulphate, $0.07 \mathrm{mM}$ EDTA, and $8 \%$ acetonitrile ( $\mathrm{pH} 4 \cdot 72$ ). We used a Waters HPLC with Amperometric detector M-460 at $+0.60 \mathrm{~V}$ and a reversed phase column (Supelcosil LC-18, $3 \mu, 15 \mathrm{~cm} \times 4.6 \mathrm{~mm}$ ) purchased from Supelco Inc, Bellefonte, PA, USA. Two hundred $\mu$ l of sample was added to $50 \mu \mathrm{l}$ of a solution containing the internal standard $\mathrm{N}-\mathrm{CH}_{3}-5-\mathrm{HT}$ and $50 \mu \mathrm{l}$ of this mixture was autoinjected. The retention time for serotonin was 11 minutes and for the internal standard 15 minutes. Platelet serotonin release was calculated by subtracting the values of intraplatelet serotonin in a stimulated sample from that of the basal value in the non-stimulated sample.

\section{STATISTICAL ANALYSIS}

The data were analysed by mixed analysis of variance and Student's $t$ test.

\section{Results}

There were no significant differences between males and females, either in patients or controls (data not shown).

\section{BASAL INTRAPLATELET SEROTONIN} CONCENTRATIONS

The mean basal platelet values for serotonin were significantly increased in platelets from patients with MA compared with those from controls and patients with MwA (table 2). The values in platelets from patients with MwA did not significantly differ from those of controls.

Table 2 Basal platelet concentrations of serotonin, and platelet secretion of serotonin and platelet factor 4 after stimulation with collagen and PAF in patients suffering from migraine with or without aura and in healthy controls

\begin{tabular}{|c|c|c|c|c|c|c|}
\hline & \multicolumn{3}{|c|}{$\begin{array}{l}\text { Serotonin } \\
(\text { ng/10 } \\
\text { platelets })\end{array}$} & \multicolumn{3}{|c|}{$\begin{array}{ll}\text { Platelet factor } 4 \quad(I U / m l) & \end{array}$} \\
\hline & Controls & $\begin{array}{l}\text { Migraine } \\
\text { with aura }\end{array}$ & $\begin{array}{l}\text { Migraine } \\
\text { without aura }\end{array}$ & Controls & $\begin{array}{l}\text { Migraine } \\
\text { with aura }\end{array}$ & $\begin{array}{l}\text { Migraine } \\
\text { without aura }\end{array}$ \\
\hline $\begin{array}{l}\text { Basal value } \\
\text { Collagen: }\end{array}$ & $855(450)$ & 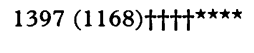 & $834(534)$ & & & \\
\hline $\begin{array}{l}0.5 \mu \mathrm{g} / \mathrm{ml} \\
2.0 \mu \mathrm{g} / \mathrm{ml} \\
\mathrm{PAF}:\end{array}$ & $\begin{array}{l}433(374) \\
543(396)\end{array}$ & $\begin{array}{l}703(667) f_{+f+\star \star \star \star \star} \\
961 \text { (891) } f^{+}+t^{\star \star \star \star}\end{array}$ & $\begin{array}{l}345(255) \\
516(360)\end{array}$ & $\begin{array}{l}4196(2300) \\
5746(2507)\end{array}$ & $\begin{array}{l}3460(2094) H^{\star \star \star} \\
5049(2454) \mathrm{H}^{\star} \dagger^{\star}\end{array}$ & $\begin{array}{l}3902(2355) \\
5991(3353)\end{array}$ \\
\hline $\begin{array}{l}0.1 \mu M \\
1 \cdot 0 \mu M\end{array}$ & $\begin{array}{l}273(391) \\
406(404)\end{array}$ & $\begin{array}{l}449(567)+f^{\star \star \star} \\
654(634)+f^{\star \star \star}\end{array}$ & $\begin{array}{l}235(284) \\
395(324)\end{array}$ & $\begin{array}{l}1319(1356) \\
3170(1875)\end{array}$ & $\begin{array}{l}1786(1586) \\
4346(2664)^{\star \star}\end{array}$ & $\begin{array}{l}2007(2270)^{\star} \\
5325(3618)+t+\star \star \star \star\end{array}$ \\
\hline
\end{tabular}

Values are means $(\mathrm{SD})$

* A statistically significant difference between a migraine group and the control group.

* A statistically significant difference between a migraine group and the

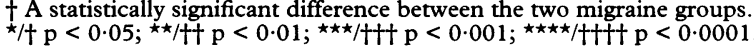


Table 3 The maximum velocity $\left(V_{\max }\right)$ and amplitude $\left(A_{\max }\right)$ of platelet aggregation induced by collagen and $P A F$ in patients with migraine with or without aura and in healthy controls

\begin{tabular}{|c|c|c|c|c|c|c|}
\hline & \multicolumn{2}{|l|}{ Controls } & \multicolumn{2}{|c|}{ Migraine with aura } & \multicolumn{2}{|c|}{ Migraine without aura } \\
\hline & $V_{\max }$ & $A_{\max }$ & $V_{\max }$ & $A_{\max }$ & $V_{\max }$ & $A_{\max }$ \\
\hline \multicolumn{7}{|l|}{ Collagen } \\
\hline $\begin{array}{l}0.5 \mu \mathrm{g} / \mathrm{ml} \\
2.0 \mu \mathrm{g} / \mathrm{ml} \\
\text { PAF }\end{array}$ & $\begin{array}{l}63.9(17.6) \\
88.3(13.3)\end{array}$ & $\begin{array}{l}59 \cdot 2(10 \cdot 2) \\
70.9(10 \cdot 7)\end{array}$ & $\begin{array}{l}63.0(24 \cdot 4) \\
89 \cdot 4(17 \cdot 6)\end{array}$ & $\begin{array}{l}58 \cdot 0(12 \cdot 3) \\
67 \cdot 8(4 \cdot 71)\end{array}$ & $\begin{array}{l}59.8(23.3) \\
82.4(18.4)\end{array}$ & $\begin{array}{l}56.7(13.7) \\
63.0(15.4)\end{array}$ \\
\hline $\begin{array}{l}0.1 \mu \mathrm{M} \\
1.0 \mu \mathrm{M}\end{array}$ & $\begin{array}{l}38 \cdot 6(15 \cdot 6) \\
84 \cdot 5(16 \cdot 3)\end{array}$ & $\begin{array}{l}15 \cdot 4(13 \cdot 7) \\
56 \cdot 0(17 \cdot 3)\end{array}$ & $\begin{array}{l}45 \cdot 4(23 \cdot 5) \\
85 \cdot 4(12 \cdot 9)\end{array}$ & $\begin{array}{l}20 \cdot 1(14 \cdot 6) \\
58 \cdot 7(16 \cdot 7)\end{array}$ & $\begin{array}{l}35.0(17.3) \\
83.4(17.9)\end{array}$ & $\begin{array}{l}16.7(18.6) \\
51.3(18.0)\end{array}$ \\
\hline
\end{tabular}

Values are means (SD). There were no statistically significant differences between the three groups.

\section{PLATELET AGGREGATION}

The $V_{\max }$ and $A_{\max }$ of platelet aggregation induced by collagen and PAF did not differ significantly between platelets from any groups (table 3).

\section{COLLAGEN-INDUCED PLATELET SECRETION}

Collagen-induced serotonin secretion was significantly increased in platelets from patients with MA compared with both those from controls and those from patients with MwA (table 2). By contrast, PF4 secretion was significantly lower in platelets from patients with MA compared with both those from MwA and controls. There were no significant differences between platelets from patients with MwA and those of controls.

\section{PAF-INDUCED PLATELET SECRETION}

PAF-induced serotonin secretion was significantly increased in platelets from patients with MA both compared with those from patients with MwA and those from controls (table 2). The PF4 secretion induced by $0 \cdot 1 \mu \mathrm{M}$ PAF was significantly increased in platelets from patients with MwA compared with controls. There was also a tendency towards an increase in platelets from patients with MA, but it did not reach statistical significance when compared with controls. The PF4-secretion induced by $1.0 \mu \mathrm{M}$ PAF was significantly increased in platelets from both migraine groups compared with controls. The secretion was also significantly higher in platelets from patients with MwA than MA.

\section{Discussion}

Our present data indicate that the characteristics of platelet function differ significantly between the two clinical types MA and MwA, as demonstrated by different profiles of stimulated secretion of platelet granules in vitro. Indeed, the substantially increased platelet content and secretion of serotonin from dense granules seems to be a specific biological marker for MA. Further, the impairment of platelet $\alpha$-granule secretion on collagen stimulation was found only in platelets from the MA group. On the other hand, enhancement in the PAF-induced platelet secretion from the $\alpha$-granules, is apparently a common feature shared by platelets from the two migraine types.

Our data thus indicate an aberrant platelet $\alpha$-granule secretion in platelets from patients with migraine, and the divergent platelet responses induced by the two agonists, PAF and collagen, suggest an abnormality in transformation of the cellular signal. It may seem abstruse that the other platelet responses did not follow the same pattern, as they are generally considered to be elicited according to the potency of the stimulus in the order: aggregation, dense granule secretion, and $\alpha$-granule secretion. ${ }^{6}$ Platelet responses do not, however, always occur in this sequential order, ${ }^{7-9}$ and furthermore the proportions between dense and $\alpha$-granule secretion may vary at different agonist concentrations. ${ }^{10}$

Our present finding of a specific platelet $\alpha$-granule hypersecretion in response to PAF is in accordance with other findings in patients with migraine of an enhanced increase in platelet cytoplasmic ionised calcium $\left(\left[\mathrm{Ca}^{2+}\right]_{\mathrm{i}}\right)$ on stimulation with PAF, but not collagen. ${ }^{11}$ Thus, the platelet hypersecretion from $\alpha$-granules induced by PAF may, at least in part, be connected to abberrant intracellular calcium transients and perhaps an enhancement in the coupling between the phosphatidylinositol cycle and $\mathrm{Ca}^{2}+$ mobilisation. This assumption is not in controversy with the diverse platelet response to collagen, as collagen only mobilises $\mathrm{Ca}^{2}{ }^{+}$weakly. ${ }^{12}$

The mechanisms behind the impairment of the collagen-induced platelet $\alpha$-granule secretion that we found solely in platelets from the MA group remain unclear. One possibility is that it may involve an anomaly of the protein kinase C pathway associated with collageninduced secretion. ${ }^{12}$ It is not inconceivable that anomalies at different steps of the transformation of the cellular signal may have a different impact on the secretion from the two granule types, as the secretion from the dense and the $\alpha$-granules has been shown to differ with regard to dependence of $\mathrm{Ca}^{2}+$ and protein kinase C. ${ }^{10}$ It seems less likely that this impairment of $\alpha$-granule secretion is due to a decreased amount of $\alpha$-granular material, because it was specific for collagen. Furthermore, it has been shown that the number of $\alpha$-granules is not decreased in patients with migraine. ${ }^{13}$

We failed to find any significant parallel changes in platelet aggregation induced by collagen or PAF. However, as quantitative measurement of platelet secretion is more sensitive than determination of platelet aggregation, it is possible that we may have failed to detect a parallel increase in platelet aggregation. Other studies have emphasised abnormalities in platelet aggregation in response to 
PAF in patients with migraine, ${ }^{14} 15$ and the issue needs further investigation.

The present findings of a specific platelet hypersensitivity to PAF in migraine, focuses attention on PAF as a possible contributor to platelet activation in migraine. To our knowledge, PAF concentrations have not been measured in migraineurs, but it is conceivable that migraine attacks may be associated with locally increased concentrations of PAF. There is evidence suggesting that the formation of PAF is stimulated by substance $\mathrm{P}^{16}$; a peptide that is released from the trigeminovascular system into the extracerebral circulation during migraine attacks. ${ }^{17}$ In this context platelets are particularly implicated as target cells for PAF, because platelets are highly sensitive to PAF compared with other blood cells. ${ }^{18}$ By inducing activation of normal human platelets in concentrations as low as 1-10 nM, PAF is the most potent platelet agonist known. ${ }^{6}$ Release of $\alpha$-granular material from hypersensitive platelets may further enhance PAF formation, as $\alpha$-granule proteins may stimulate and act chemotactically on various inflammatory cells. ${ }^{19} \mathrm{PAF}$ is indeed a potent mediator in the $\mathrm{CNS},{ }^{20}$ and further studies performed during attack may clarify the possible role of PAF in migraine.

The increased serotonin secretion found in platelets from patients with MA, was associated with similarly increased basal intraplatelet serotonin concentration as also indicated by our previous data. ${ }^{13}$ Hence, the increased platelet serotonin secretion in MA seems to be due to increased platelet serotonin content rather than a hypersecretory response itself.

Our present results confirm previous findings that in MA there is an increased number of platelet dense granules, which contain the secretable pool of platelet serotonin. ${ }^{13}$ This is not likely to be the sole explanation of the increased intraplatelet levels in MA, however, because the number of platelet dense granules was similarly increased in MwA. It is possible that the different platelet serotonin concentrations in MA and MwA may reflect different serotonin turnover in the two syndromes. Platelets have a rapid uptake mechanism for serotonin, and it is possible that increased platelet serotonin concentrations may be a reflection of increased circulating serotonin concentrations. This assumption is in agreement with the findings of Fontes Ribeiro et $a l^{21}$ of increased serum serotonin during the attack-free period in MA but not in MwA. Ferrari et $a l^{22}$ on the other hand, have reported that between attacks plasma serotonin concentrations were decreased in both types of migraine. In parallel, they found increased concentrations of the serotonin metabolite, 5-hydroxyindole acetic acid (5HIAA), only in classic migraine, and it is possible that the discrepant findings may in part be because blood samples were taken at different time points, thus reflecting different phases of serotonin metabolism. By contrast with our present results Ferrari et al also found normal platelet serotonin concentra- tions in both migraine types. A factor that may in part explain why our findings differ is that we took into account variations in platelet serotonin during the menstrual cycle.

The diverse patterns of platelet content and secretion of serotonin in the two migraine types may be a reflection of different serotonin turnover, possibly also in the CNS. An increased serotonin turnover in MA may be related to the lower frequency, duration, and pain intensity of attacks reported in this migraine type ${ }^{23}$; also demonstrated in our patients (table 1). Further, considering that serotonin infusions have been shown to relieve migraine ${ }^{24}$ an enhanced serotonin release from platelets may alleviate the MA attack.

Dr D'Andrea is a member of "Centro Interuniversitario di Ricerca Cefalee e Disordini Adattativi (UCADH)" (Interuniversity Center of Research in Headache and Adaptive Disorders).

1 Humphrey PPA. 5-Hydroxytryptamine and the pathophysiology of migraine. $\mathcal{F}$ Neurol 1992;238:S38-S44.

2 Malmgren R, Hasselmark L. The platelet and the neuron: two cells in focus in migraine. Cephalalgia 1988;8:7-24.

3 de Belleroche J, Joseph R, D'Andrea G. Platelets and migraine. In: Olesen J, Tfelt-Hansen P, Welch KMA, eds. The headaches. New York: Raven Press, 1993: 185-91.

4 Headache Classification Committee of the International Headache Society. Classification and diagnostic criteria for headache disorders, cranial neuralgias and facial pain. Cephalalgia 1988;8 (suppl 7):1-96.

5 D'Andrea G, Welch KMA, Grunfeld S, Joseph R, NagelLeiby S. Serotonin (5-HT) and 5-hydroxyindoleacetic acid (5-HIAA) platelet content in normal subjects. Thromb Res 1987;48:261-4.

6 Siess W. Molecular mechanisms of platelet activation. Physiol Rev 1989;69:58-178.

7 Lages B. In vitro platelet responses: dense granule secretion. In: Holmsen $\mathrm{H}$, ed. Platelet responses and metabolism, Vol I: Responses. Boca Raton, Florida: CRC Press Inc, 1986:115-43.

8 Malmgren R. ATP-secretion occurs as an initial response in collagen induced platelet activation. Thromb Res 1986;43:445-53

9 Pengo V, Boschello M, Baca M, et al. A brief contact of native whole blood with adenosine diphosphate (ADP) promotes the release of the contents of platelet alpha granules but not dense bodies and increases platelet
retention time to glass bead columns. Folia Haematol retention time to glass b
(Leipz) 1990;117:359-64.

10 Coorssen JR, Davidson MML, Haslam RJ. Factors affecting dense and $\alpha$-granule secretion from electropermeabilized human platelets: $\mathrm{Ca}^{2+}$-independent actions of phorbol ester and GTPYS. Cell Regul 1990;1:1027-41.

11 Joseph R, Welch KMA, Grunfeld S, Oster SB, D’Andrea $\mathrm{G}$. Cytosolic ionized calcium homeostasis in platelets: an abnormal sensitivity to PAF-activation in migraine. Headache 1988;28:396-402.

12 Karniguan A, Grelac F, Levy-Toledano S, Legrand YJ, Rendu F. Collagen-induced platelet activation mainly involves the protein kinase $C$ pathway. Biochem $f$ 1990;268:325-31.

13 D'Andrea G, Welch KMA, Riddle JM, Grunfeld S, Joseph R. Platelet serotonin metabolism and ultrastructure in migraine. Arch Neurol 1989;46:1187-9.

14 Joseph R, Welch KMA, D'Andrea G, Levine SR. Sensitivity to PAF is increased in migraine patients. Sensitivity to PAF is increased
Thromb Haemost $1987 ; 57: 125$.

15 Kovacs K, Herman F, Filep J, Jelencsik I, Magyar K, Csanda E. Platelet aggregation of migraineurs during and between attacks. Cephalalgia 1990;10:161-5.

16 Karmeli F, Eliakim R, Okon E, Rachmilewitz D. Gastric mucosal damage by ethanol is mediated by substance $P$ and prevented by ketotifen, a mast cell stabilizer. Gastroenterology 1991;5:1206-16.

17 Goadsby PJ, Edvinsson L, Ekman R: Vasoactive peptide release in the extracerebral circulation of humans during migraine headache. Ann Neurol 1990;28:183-7.

18 Koltai M, Hosford D, Guinot P, Esanu A, Braquet P. Platelet activating factor (PAF). A review of its effects, antagonists and possible future clinical implication (Part I). Drugs 1991;42:9-29.

19 Gresele $P$. The platelet in asthma. In: Page CD, ed. The platelet in health and disease. Oxford: Blackwell Scientific 1989;132-57. 
20 Lindsberg PJ, Hallenbeck JM, Feuerstein G. Platelet-activating factor in stroke and brain injury. Ann Neurol 1991;30:117-29.

21 Fontes Ribeiro CA, Cotrim MD, Morgadinho MT, Ramos MI, Seabra Santos E, Macedo TRA. Migraine, serum serotonin and platelet $5-\mathrm{HT}_{2}$ receptors. Cephalalgia 1990;10:213-9.

22 Ferrari MD, Odink J, Tapparelli C, Van Kempen GMJ,
Pennings EJM, Bruyn GW. Serotonin metabolism in migraine. Neurology 1989;39:1239-42.

23 Manzoni GC, Farina S, Granella F, Alfieri M, Bisi $M$. Classic and common migraine, suggestive clinical evidence of two separate entities. Func Neurol 1986;1: $112-22$.

24 Lance JW. 5-Hydroxytryptamine and its role in migraine. Eur Neurol 1991;31:279-81. 